\title{
ДИНАМИКА СЕЛЬХОЗУГОДИЙ РОССИЙСКОЙ ФЕДЕРАЦИИ
}

Мазуркин Петр Матвеевич

д-р техн. наук, проф., зав. кафедрой природообустройства и геодезии, Поволжский государственный технологический университет, Йошкар-Ола

E-mail: kaf_po@mail.ru

\section{DYNAMICS FARMLAND RUSSIAN FEDERATION}

Mazurkin Peter Matveevich

Dr. Sc. Sciences, prof., Head. of the Department of Environmental Engineering and Geodesy, Volga State University of Technology, Yoshkar-Ola

Приведены закономерности динамики показателей сельхозугодий России за 1990-2012 годы и показана активность пашни, сенокосов и пастбищ, залежи

The regularities of the dynamics of indicators of agricultural Russia for 19902012 years and shows the activity of arable land, hayfields and pastures, fallow

Ключевые слова: сельхозугодия; площадь; динамика; закономерности

Keywords: farmland; area; dynamics; regularities

Введение. По данным земельного кадастра одного субъекта Российской Федерации динамика землепользования нами была рассмотрена три раза: вначале был период 1985-1999 гг. [3, 10], второй раз 1985-2005 гг. [13, 14]. В статье [11] дается третья итерация по динамическому ряду 1985-2012 гг. Методология факторного анализа показателей земельного кадастра изложена в [1, 3-18].

В предыдущей статье в данный сборник были проанализированы тенденции пользования земельными ресурсами в России за 1990-2012 гг.

Цель статьи - на табличных данных [2] показать методологию анализа динамики сельскохозяйственных угодий (СХУ) Российской Федерации.

Методология. В большинстве случаев для идентификации закономерностей земельного кадастра достаточна формула асимметричного вейвлет-сигнала

$$
y=\sum_{i=1}^{m} y_{i}, y_{i}=a_{1 i} t^{a_{2 i}} \exp \left(-a_{3 i} t^{a_{4 i}}\right) \cos \left(\pi t /\left(a_{5 i}+a_{6 i} t^{a_{7 i}}\right)-a_{8 i}\right),
$$

где $y$ - изучаемый показатель, $t$ - время, лет, $a_{1} \ldots a_{8}$ - параметры модели (1).

В общей стохастической волновой функции (1) не волновые части (тренды) становятся частными случаями и показывают детерминированное на интервале времени измерений поведение объекта исследования. Составная статистическая модель (1), включающая члены с номерами $i$ и количеством $m$, по- 
зволяет идентифицировать поведение многих физических, биологических и экологических. социально-экономических и иных объектов.

Физико-математический подход предполагает понимание смысла динамического ряда как отражения какого-то составного реального процесса или же множества последовательно и параллельно происходящих природных и/или природно-антропогенных реальных процессов.

Исходные данные. К табличным данным за 2012 год [2] (табл. 1) дополнительно были введены три относительных показателя: активность пашни в площади СХУ; активность сенокосов и пастбищ в СХУ; активность залежи.

Таблица Ошибка! Текст указанного стиля в документе отсутствует.. Динамика площади сельскохозяйственных угодий в границах Российской Федерации за период с 1990 по 2012 год (с землями личного пользования)

\begin{tabular}{|c|c|c|c|c|c|c|c|c|}
\hline \multirow[b]{2}{*}{ Год } & \multirow{2}{*}{$\begin{array}{c}\text { Время } \\
t, \text { лет }\end{array}$} & \multirow{2}{*}{$\begin{array}{c}\text { Сельскохозяй } \\
\text { ственные } \\
\text { угодья } S_{C X Y}\end{array}$} & \multicolumn{3}{|c|}{ в том числе, тыс. га } & \multicolumn{3}{|c|}{ Доля (активность) в СХУ, \% } \\
\hline & & & $\begin{array}{c}\text { пашня } \\
S_{\Pi}\end{array}$ & $\begin{array}{c}\text { сенокосы } \\
\text { и пастб. } S_{C \Pi}\end{array}$ & $\begin{array}{c}\text { залежь } \\
S_{3}\end{array}$ & пашня & $\begin{array}{c}\text { сенокосы } \\
\text { и пастб. } \alpha_{C \Pi}\end{array}$ & $\begin{array}{c}\text { залежь } \\
\alpha_{3}\end{array}$ \\
\hline 1990 & 0 & 222409.2 & 132304.2 & 87899.5 & 347.2 & 59.49 & 39.52 & 0.16 \\
\hline 1991 & 1 & 222407.9 & 132068.7 & 86860.2 & 374.7 & 59.38 & 39.05 & 0.17 \\
\hline 1992 & 2 & 222486.3 & 132004.6 & 88081.1 & 393.4 & 59.33 & 39.59 & 0.18 \\
\hline 1993 & 3 & 222122.0 & 131587.3 & 88248.8 & 481.2 & 59.24 & 39.73 & 0.22 \\
\hline 1994 & 4 & 221794.6 & 130656.2 & 88012.4 & 1097.8 & 58.91 & 39.68 & 0.49 \\
\hline 1995 & 5 & 221985.2 & 130197.6 & 88229.2 & 1456.4 & 58.65 & 39.75 & 0.66 \\
\hline 1996 & 6 & 221634.2 & 128870.9 & 88783.0 & 2003.1 & 58.15 & 40.06 & 0.90 \\
\hline 1997 & 7 & 221491.6 & 127822.8 & 89220.9 & 2501.9 & 57.71 & 40.28 & 1.13 \\
\hline 1998 & 8 & 221161.8 & 126488.6 & 89943.8 & 2874.6 & 57.19 & 40.67 & 1.30 \\
\hline 1999 & 9 & 221151.3 & 125331.9 & 90585.6 & 3360.8 & 56.67 & 40.96 & 1.52 \\
\hline 2000 & 10 & 221088.8 & 124373.8 & 90923.4 & 3927.2 & 56.26 & 41.13 & 1.78 \\
\hline 2001 & 11 & 221003.6 & 123859.6 & 91143.0 & 4143.3 & 56.04 & 41.24 & 1.87 \\
\hline 2002 & 12 & 220896.2 & 123464.4 & 91351.4 & 4245.0 & 55.89 & 41.35 & 1.92 \\
\hline 2003 & 13 & 220832.6 & 122558.4 & 91903.6 & 4556.3 & 55.50 & 41.62 & 2.06 \\
\hline 2004 & 14 & 220729.7 & 122146.0 & 92023.7 & 4750.2 & 55.34 & 41.69 & 2.15 \\
\hline 2005 & 15 & 220679.0 & 121780.9 & 92098.8 & 4998.9 & 55.18 & 41.73 & 2.27 \\
\hline 2006 & 16 & 220632.7 & 121573.9 & 92117.1 & 5144.3 & 55.10 & 41.75 & 2.33 \\
\hline 2007 & 17 & 220567.9 & 121573.5 & 92094.5 & 5105.7 & 55.12 & 41.75 & 2.31 \\
\hline 2008 & 18 & 220491.6 & 121648.9 & 92052.0 & 4998.0 & 55.17 & 41.75 & 2.27 \\
\hline 2009 & 19 & 220461.6 & 121648.7 & 92053.0 & 4965.2 & 55.18 & 41.75 & 2.25 \\
\hline 2010 & 20 & 220396.3 & 121433.9 & 92059.5 & 5103.3 & 55.10 & 41.77 & 2.32 \\
\hline 2011 & 21 & 220272.1 & 121444.9 & 92028.3 & 4996.9 & 55.13 & 41.78 & 2.27 \\
\hline 2012 & 22 & 220220.8 & 121459.6 & 91996.7 & 4960.2 & 55.15 & 41.32 & 2.25 \\
\hline
\end{tabular}

Динамика площади СXУ. Графики на рисунке 1 получают формулу

$$
\begin{array}{r}
S_{C X Y}=S_{C X Y 1}+S_{C X Y 2}+S_{C X Y 3}, \\
S_{C X Y 1}=2,22404 \cdot 10^{5} \exp \left(-1,23910 \cdot 10^{-6} t^{2,65877}\right),
\end{array}
$$




$$
\begin{aligned}
& S_{C X У 2}=-6,35842 \cdot 10^{5} t^{5,98022} \exp \left(-10,75363 t^{0,27015}\right), \\
& S_{C X У 3}=A \cos (\pi t / p-3,46654), A=624,43891 t^{0,51299} \exp (-0,40512 t), \\
& p=0,53290+0,096619 t,
\end{aligned}
$$

где $A$ - амплитуда (половина) колебания, т. га, $p$ - полупериод колебания, лет.

В этом трехчленном тренде первая составляющая является экспоненциальным законом гибели, а второй член показывает кризисное возбуждение сельского хозяйства России. При этом третий член является позитивно направленным колебанием волновой адаптации России к площади СХУ.

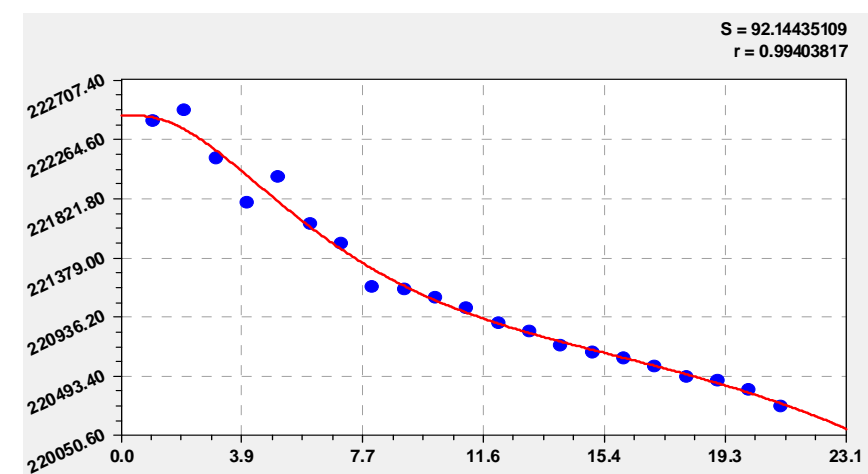

Двухчленный тренд динамики СХУ

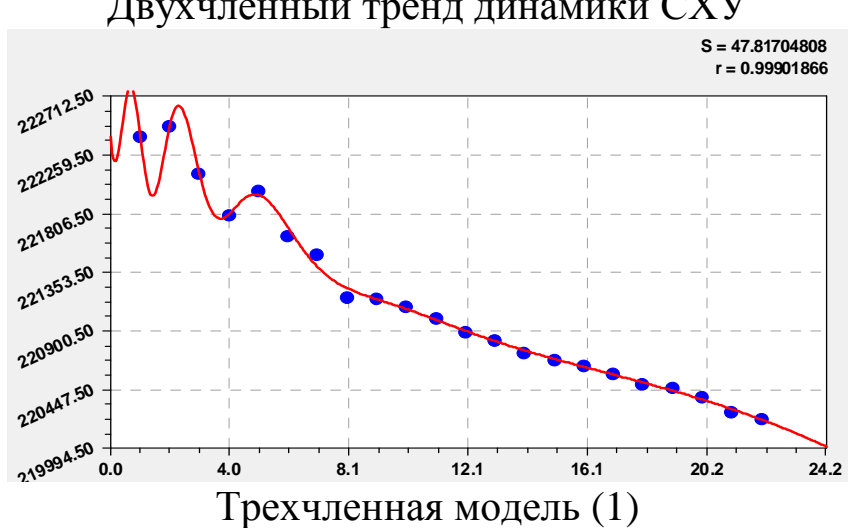

Трехчленная модель (1)

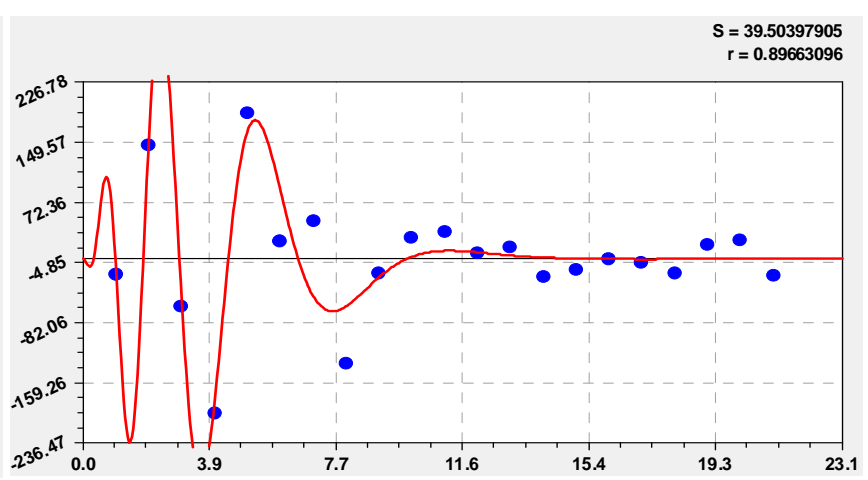

Колебательное возмущение СХУ

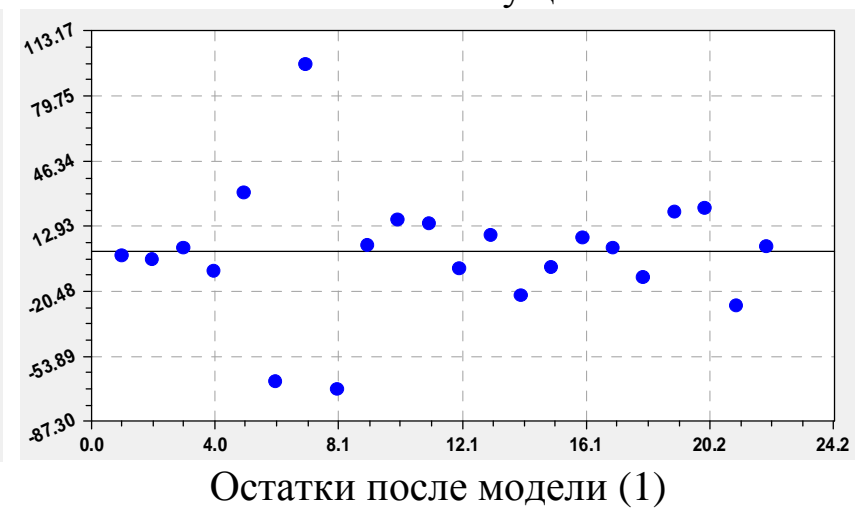

Рисунок 1. Графики динамики площади СХУ Российской Федерации

Коэффициент корреляции модели (1) равен 0,9990 и это относит формулу к сверхсильным факторным связям. По остаткам заметна и вторая волна возмущения. Однако обе волны уже были в прошлом, поэтому на прогноз влияет только тренд, из которого нужно какими-то мерами уменьшить до нуля влияние кризисной составляющей. Тогда останется естественная первая составляющая.

Динамика пашни. Она характеризуется (рис. 2) уравнением вида

$$
\begin{gathered}
S_{\Pi}=S_{\Pi 1}+S_{\Pi 2}+S_{\Pi 13}, \\
S_{\Pi 1}=1,32261 \cdot 10^{5} \exp \left(-0,00076699 t^{1,26813}\right), \\
S_{\Pi 2}=-2,43141 \cdot 10^{6} t^{9,70215} \exp \left(-14,10442 t^{0,30355}\right),
\end{gathered}
$$




$$
\begin{aligned}
& S_{\Pi 3}=A \cos (\pi t / p+0,77911), A=-7,39952 t^{2,44566} \exp (-0,22753 t), \\
& p=-12,25040+13,69847 t^{0,030622} .
\end{aligned}
$$

Оба уравнения (1) и (2) схожи по конструкции. Но имеются и различия.

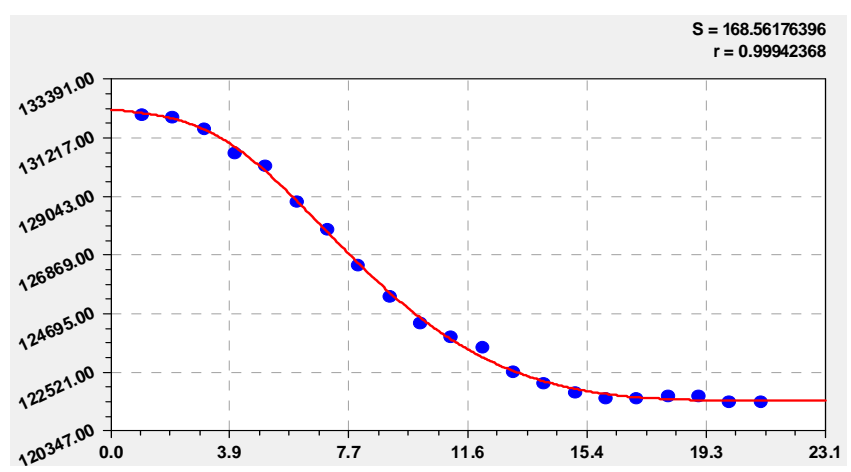

Двухчленный тренд динамики пашни
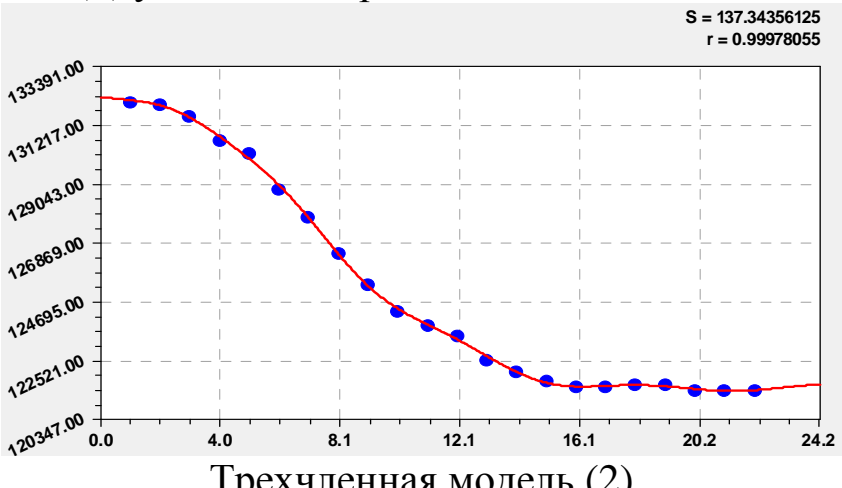

Трехчленная модель (2)

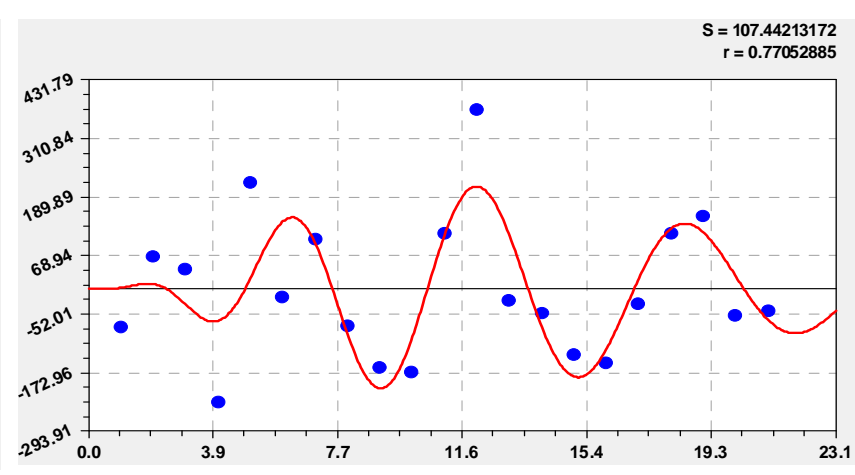

Колебательное возмущение пашни

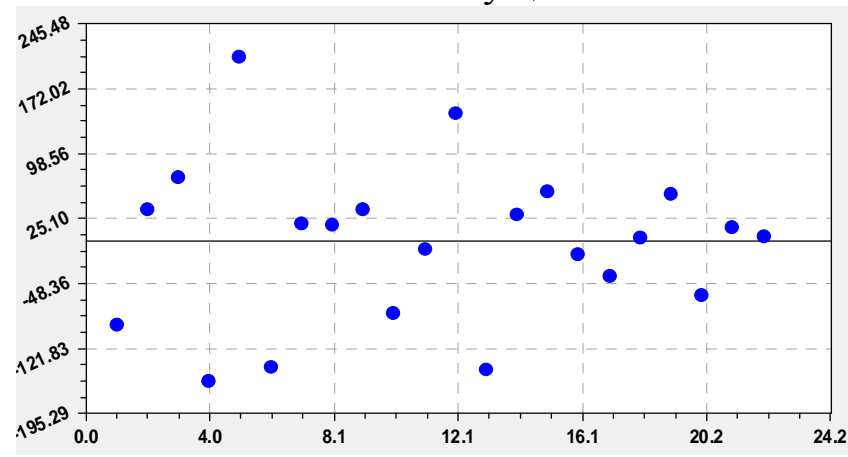

Остатки после модели (2)

Рисунок 2. Графики динамики площади пашни Российской Федерации

Формула (2) получила отрицательное колебание, поэтому пашни получают в России отрицательную адаптацию (люди не знают, что творят). По графику на рисунке 2 ожидается, что колебание продолжится почти до 2020 г. Остатки показывают, что в прошлом было еще колебания, но они не влияют на будущее.

Динамика сенокосов и пастбищ. Она дается (рис. 3) формулой, с постоянной частотой одной волны колебания в $2 \times 2,07489 \approx 4,15$ года, вида

$$
\begin{aligned}
& S_{C \Pi}=S_{C \Pi 1}+S_{C \Pi 2}+S_{C \Pi 3}, \\
& S_{C \Pi 1}=87840,704 \exp \left(5,05087 \cdot 10^{-6} t^{2,68171}\right), \\
& S_{C \Pi 2}=3,67655 \cdot 10^{5} t^{12,41230} \exp \left(-15,63607 t^{0,33028}\right), \\
& S_{C \Pi 3}=A \cos (\pi t / p-1,12647), \\
& A=-3043,5552 t^{0,96454} \exp (-1,05597 t), p=2,07489 .
\end{aligned}
$$

Как видно из рисунка 3 , с годами происходит снижение площади СХУ и пашни, но сенокосы и пастбища по площади возрастают. При этом их качество по продуктивности травы снижается [6-8]. Поэтому снижается и общий валовой сбор кормовых травяных ресурсов в стране. 

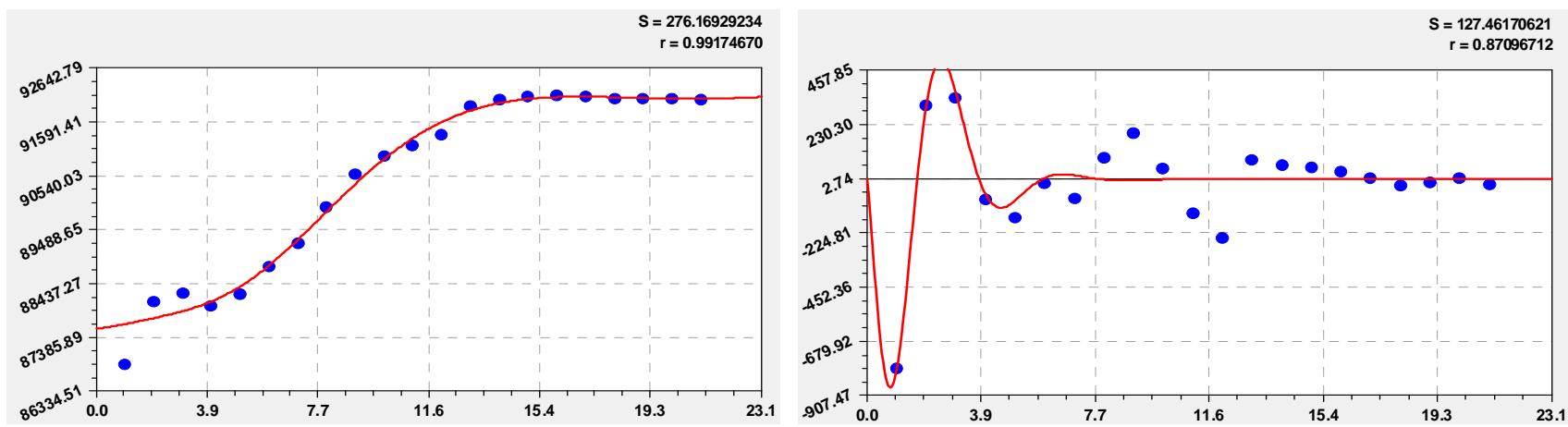

Двухчленный тренд сенокосов и пастбищ

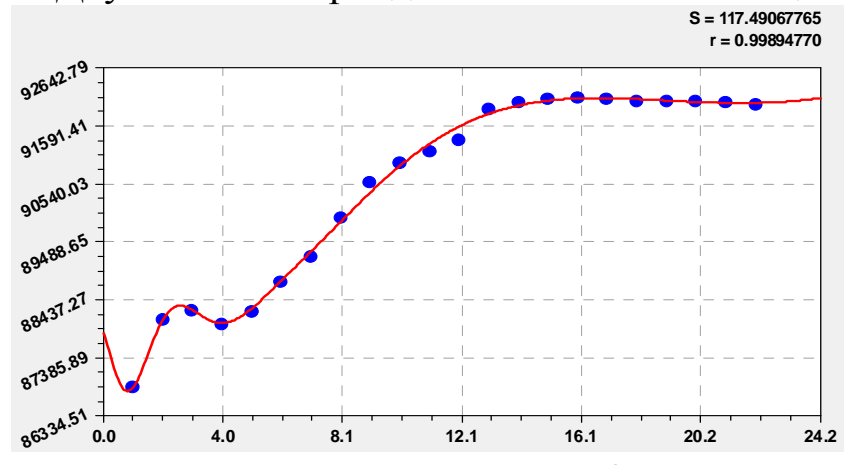

Трехчленная модель (3)

Колебание площади сенокосов и пастбищ

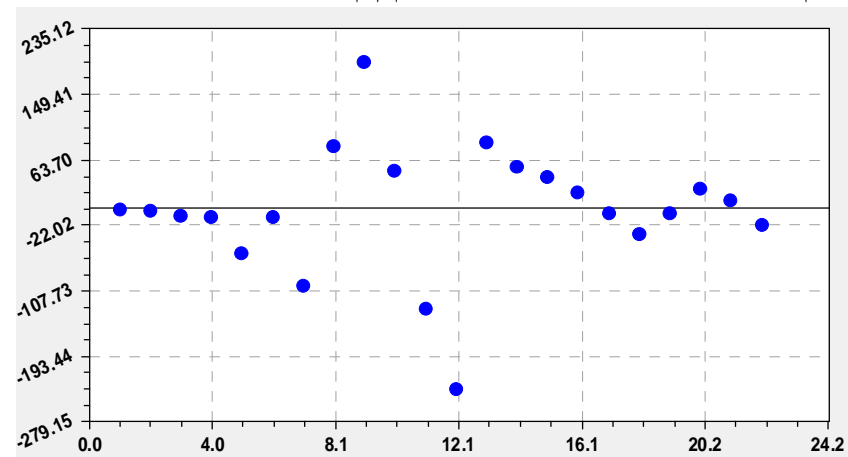

Остатки после модели (3)

Рисунок 3. Графики динамики площади сенокосов и пастбищ Российской Федерации

По остаткам в прошлом была еще одна импульсная функция, но оба колебания ныне имеют историографическое значение и на прогноз [12] не влияют.

Динамика залежи. Площадь залежей, то есть фактически «отходов» полеводства и растениеводства, нарастает (рис. 4) по нижеследующей формуле.
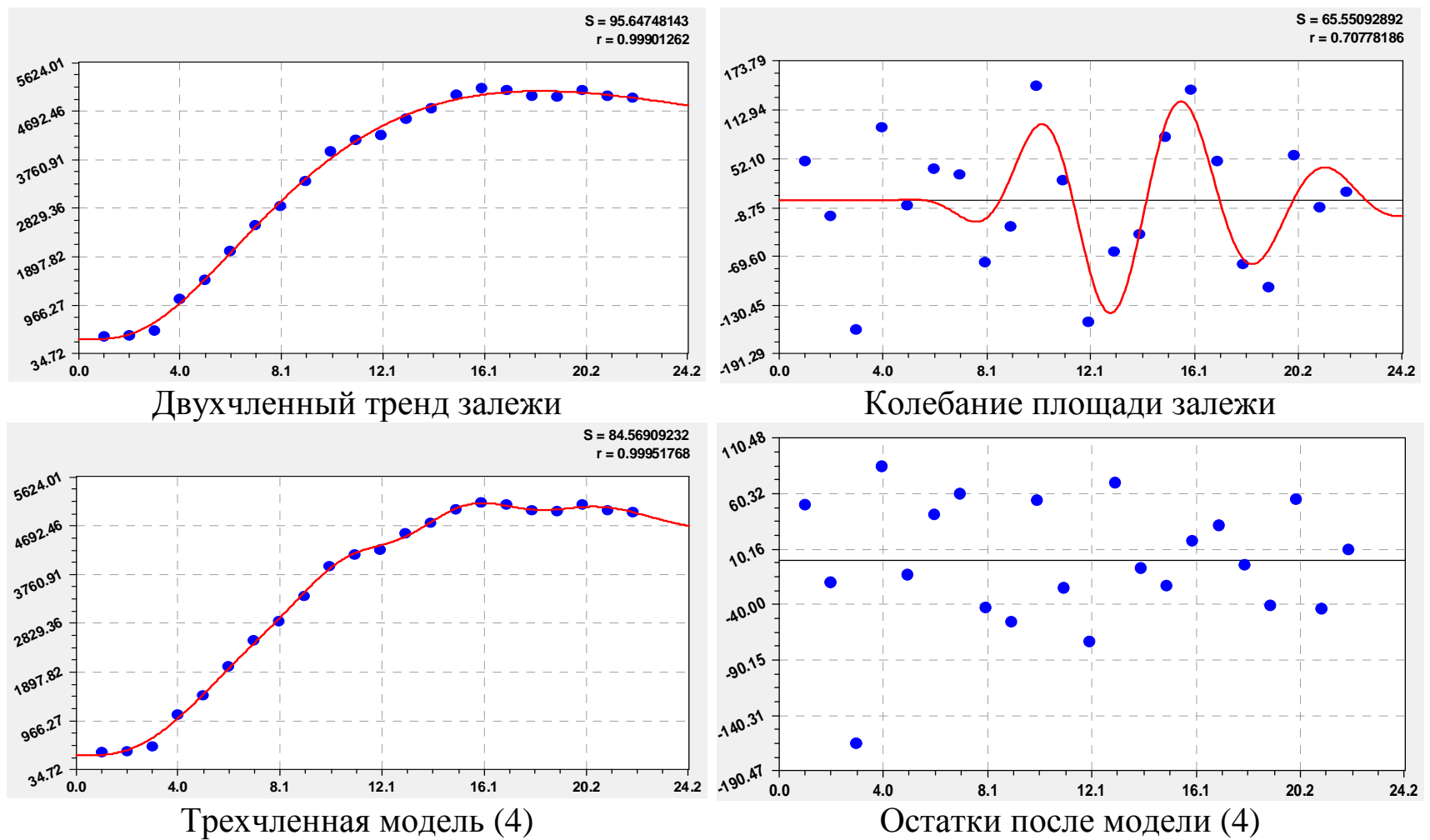

Рисунок 4. Графики динамики площади залежи Российской Федерации 


$$
\begin{gathered}
S_{3}=S_{31}+S_{32}+S_{33}, \\
S_{31}=315,63166 \exp \left(2,66640 \cdot 10^{-5} t^{2,40353}\right), \\
S_{32}=5,66516 \cdot 10^{7} t^{7,79348} \exp \left(-15,76745 t^{0,24391}\right), \\
S_{33}=A \cos (\pi t / p-4,88418), \\
A=18104,122 t^{23,86912} \exp \left(-26,50026 t^{0,35642}\right), p=2,82100 .
\end{gathered}
$$

Волна возмущения влияет до 2016 г. а вторая волна была в прошлом.

Далее примем площадь СХУ за базовый показатель.

Доля в площади СХУ пашни. Это отношение, являющееся активностью влияния фактора, меняется (рис. 5) также по трехчленной формуле вида

$$
\begin{aligned}
& \quad \alpha_{\Pi}=\alpha_{\Pi 1}+\alpha_{\Pi 2}+\alpha_{\Pi 3} \\
& \alpha_{\Pi 1}=59,45198 \exp \left(-0,00048481 t^{1,48659}\right) \\
& \alpha_{\Pi 2}=-0,0023852 t^{5,21983} \exp \left(-0,83199 t^{0,79351}\right) \\
& \alpha_{\Pi 3}=A \cos (\pi t / p-5,07826), A=-7,36758 \cdot 10^{-13} t^{17,45867} \exp \left(-1,35090 t^{1,02828}\right), \\
& p=1,23022+0,023507 t^{1,28888}
\end{aligned}
$$

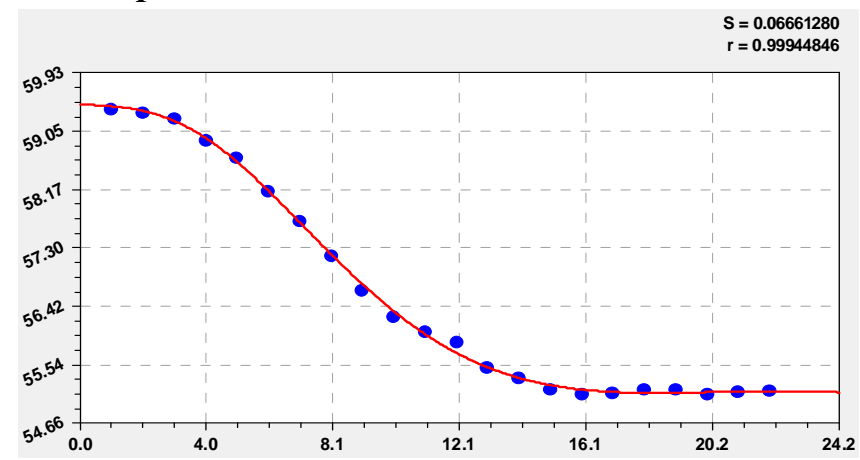

Двухчленный тренд доли пашни в СХУ
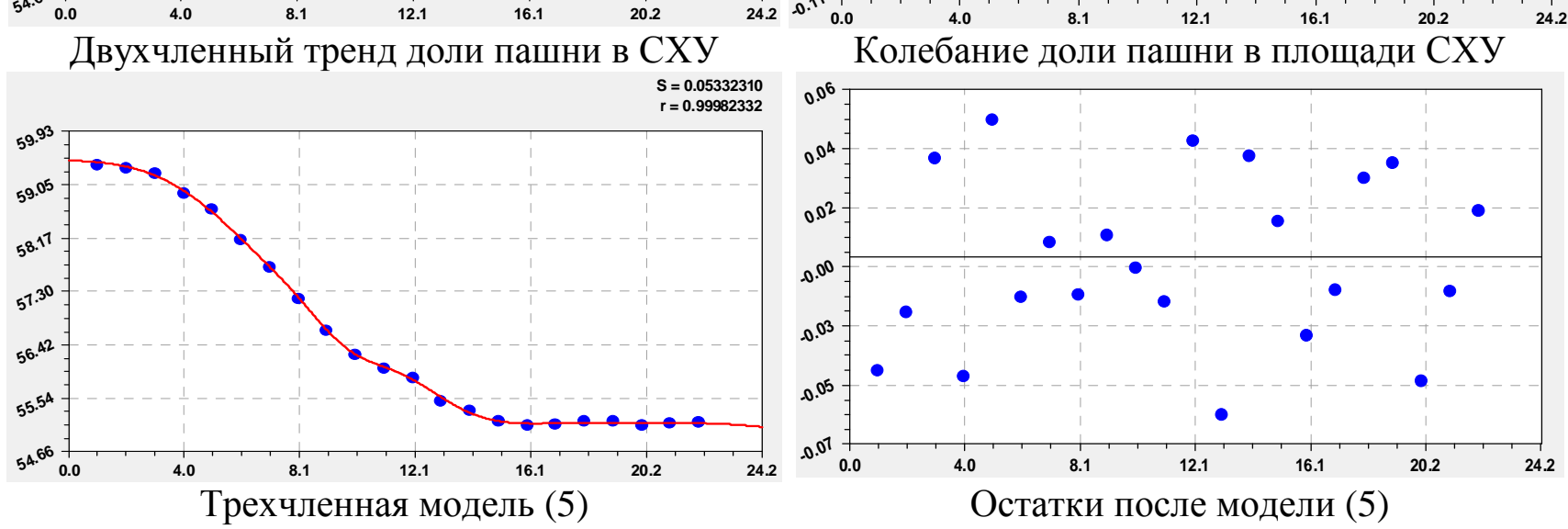

Рисунок 5. Графики динамики доли площади пашни в СХУ Российской Федерации

Первая составляющая всегда показывает естественную тенденцию, а вторая и последующие члены характеризуют, как правило, антропогенное воздействие. В формуле (5) вторая и третья составляющие, то есть влияние человеческого фактора, из-за отрицательного знака приобретают кризисный характер. 
Доля в СХУ сенокосов и пастбищ. Здесь (рис. 6) получилась четырехчленная формула с положительным антропогенным влиянием

$$
\begin{gathered}
\alpha_{C \Pi}=\alpha_{C \Pi 1}+\alpha_{C \Pi 2}+\alpha_{C \Pi 3}+\alpha_{C \Pi 4}, \\
\alpha_{C \Pi 1}=39,78544 \exp (-0,022759 t), \\
\alpha_{C \Pi 2}=0,59557 t^{1,27737} \exp \left(-0,0056745 t^{1,50734}\right), \\
\alpha_{C \Pi 3}=A_{1} \cos \left(\pi t / p_{1}-4,70656\right), A_{1}=45,50888 \exp \left(-4,44334 t^{0,16830}\right), \\
p_{1}=-0,10294+1,53487 t^{0,24453}, \alpha_{C \Pi 4}=A_{2} \cos \left(\pi t / p_{2}+3,16585\right), \\
A_{2}=-4,35733 \cdot 10^{-8} t^{5,32386}, p_{2}=26,40508-0,66114 t^{1,05189} .
\end{gathered}
$$

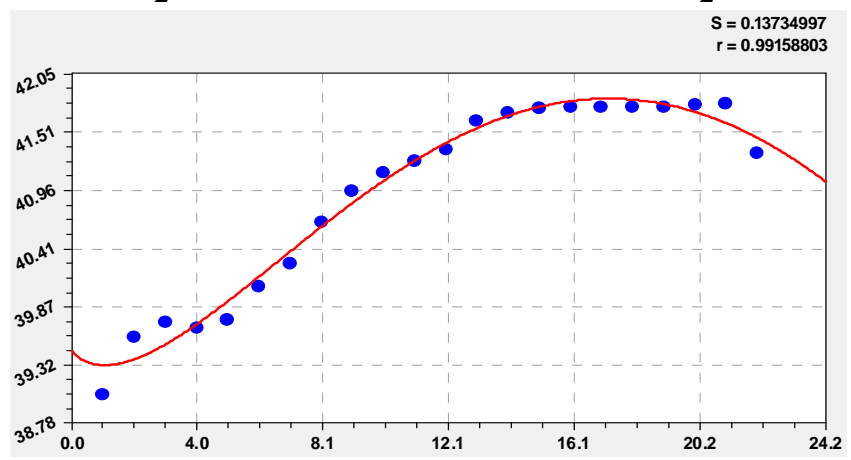

Двухчленный тренд доли сенокосов и пастбищ
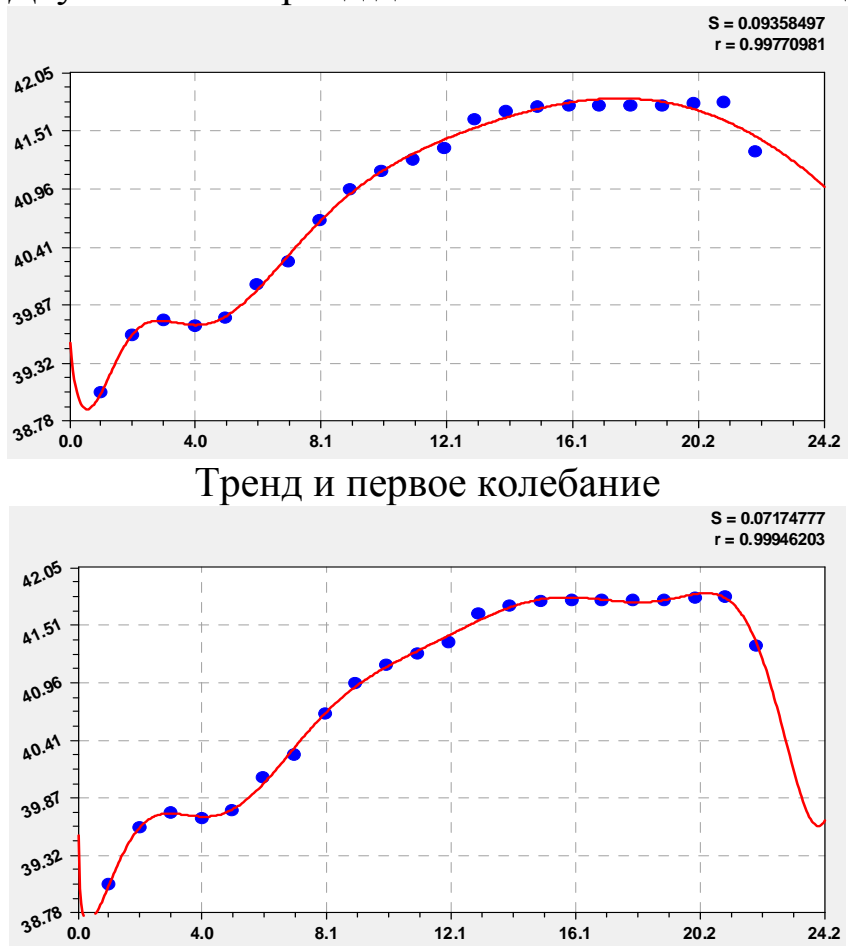

Четырехчленная модель (6)

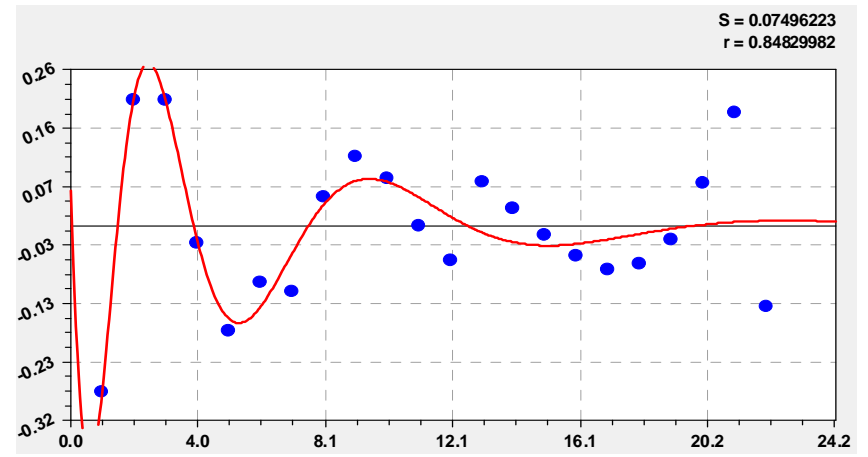

Первое колебание сенокосов и пастбищ

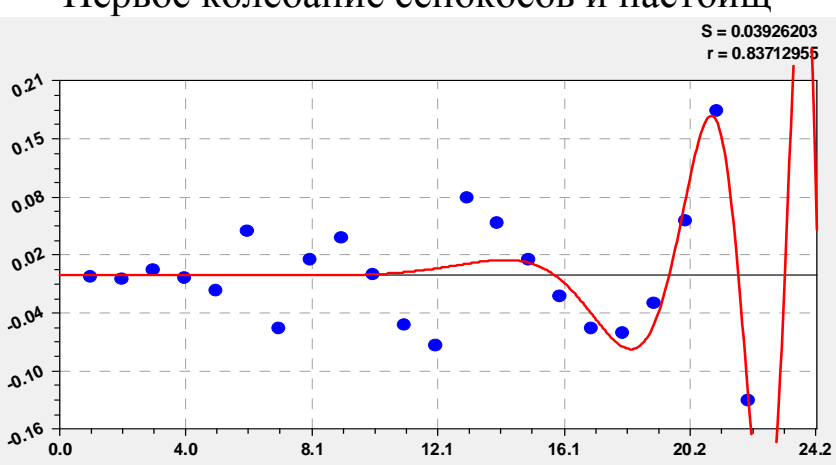

Второе колебание сенокосов и пастбищ

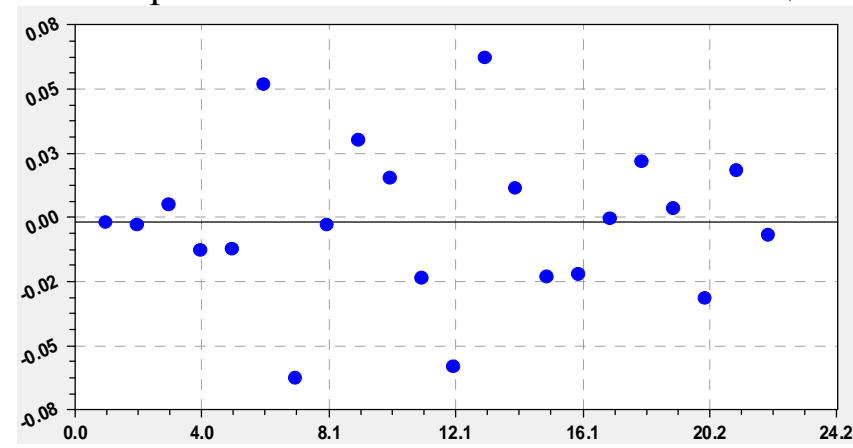

Остатки после модели (6)

Рисунок б. Графики динамики доли сенокосов и пастбищ в СХУ Российской Федерации

Таким образом, системный кризис вначале положительно повлиял на рост площади под сенокосами и пастбищами. При этом в России мало осталось улучшенных сенокосов и высокопродуктивных по травяному покрову пастбищ. А с 2002 г. нарастает тремор, и кормопроизводство может войти в ступор. 
Доля в СХУ залежи. На рисунке 7 даны графики динамики активности площади под залежи относительно СХУ также по четырехчленной формуле

$$
\begin{aligned}
& \alpha_{3}=\alpha_{31}+\alpha_{32}+\alpha_{33}+\alpha_{34}, \\
& \alpha_{31}=0,00024716 \exp \left(1,26290 t^{0,56976}\right), \\
& \alpha_{32}=0,045265 t^{1,80013} \exp \left(-0,014582 t^{1,56692}\right), \\
& \alpha_{33}=A_{1} \cos \left(\pi t / p_{1}-0,66312\right), A_{1}=0,20193 \exp (-0,36924 t), \\
& p_{1}=2,97927, \alpha_{34}=A_{2} \cos \left(\pi t / p_{2}+0,16821\right), \\
& A_{2}=-1,17883 \cdot 10^{-5} t^{5,62308} \exp (-0,44804 t), p_{2}=3,65992-0,030870 t .
\end{aligned}
$$
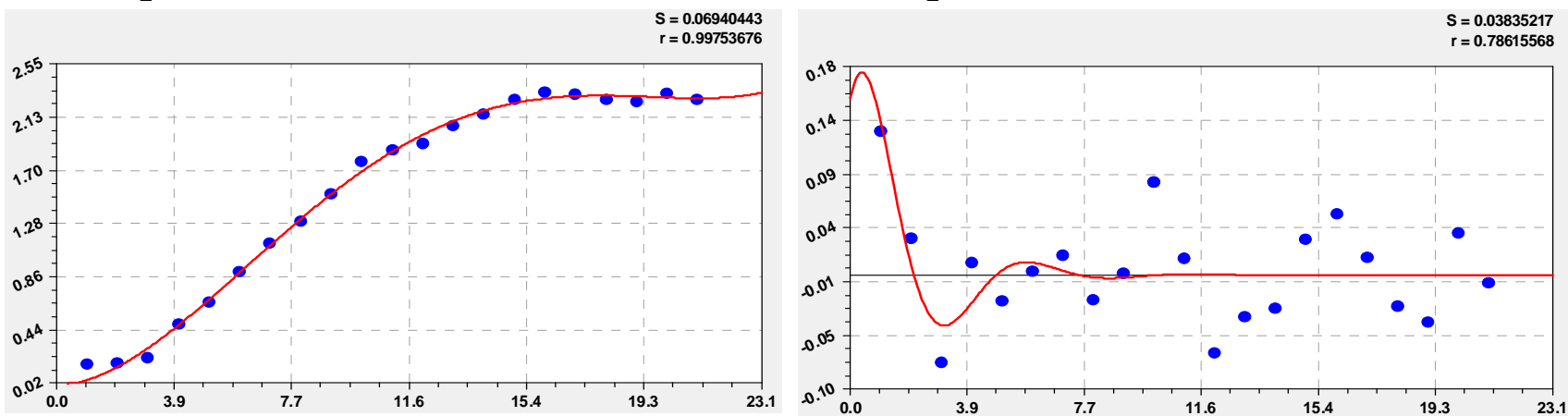

Двухчленный тренд доли залежи в СХУ

$\mathrm{S}=0.04899468$

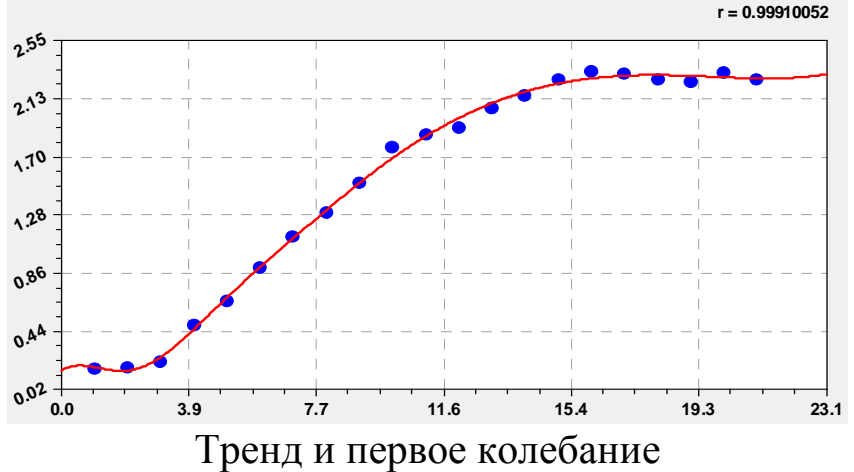

Первое колебание доли залежи в СХУ

$S=0.02513323$
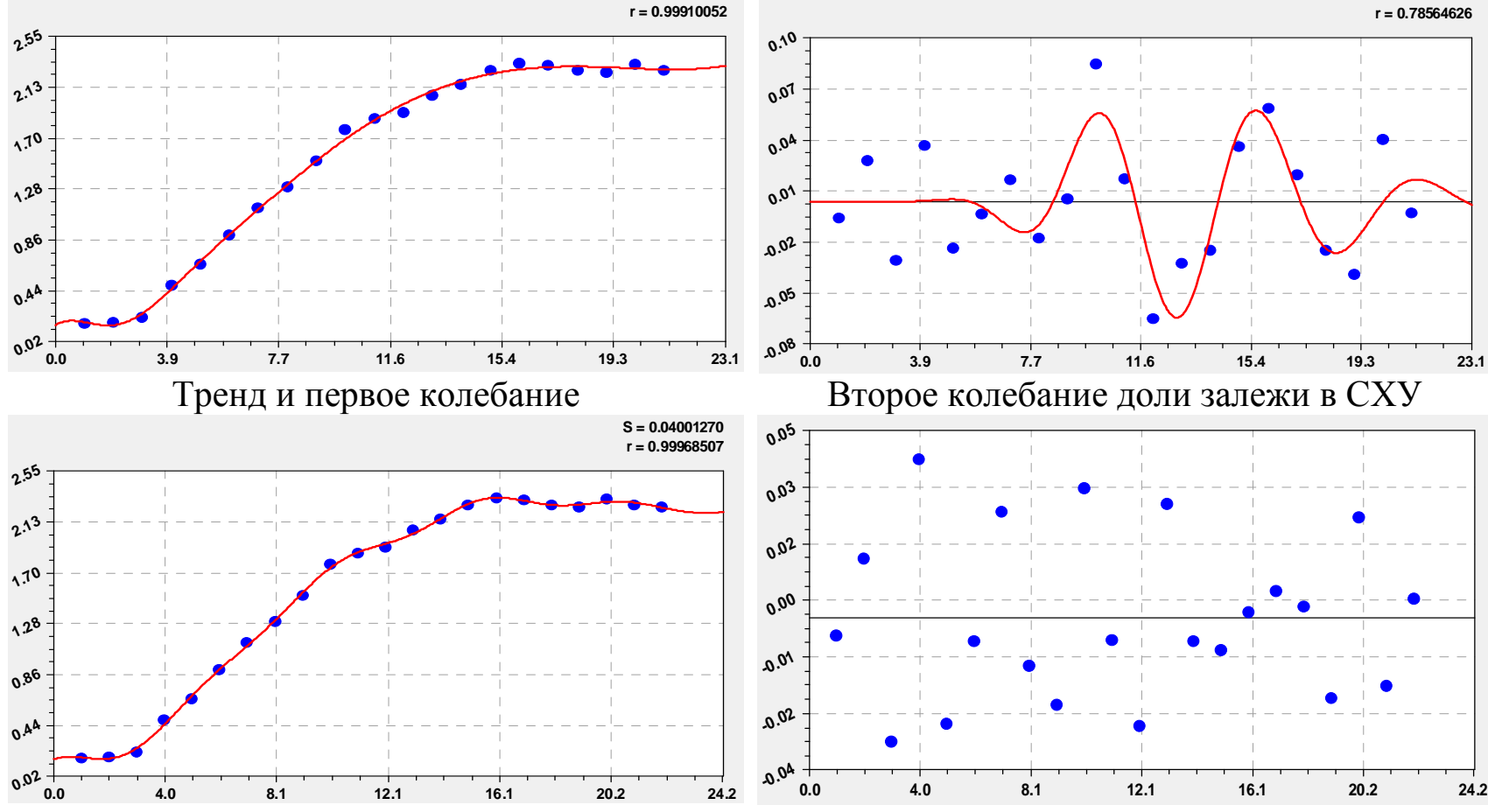

Четырехчленная модель (7)

Влорое колебание доли залежи в СХУ

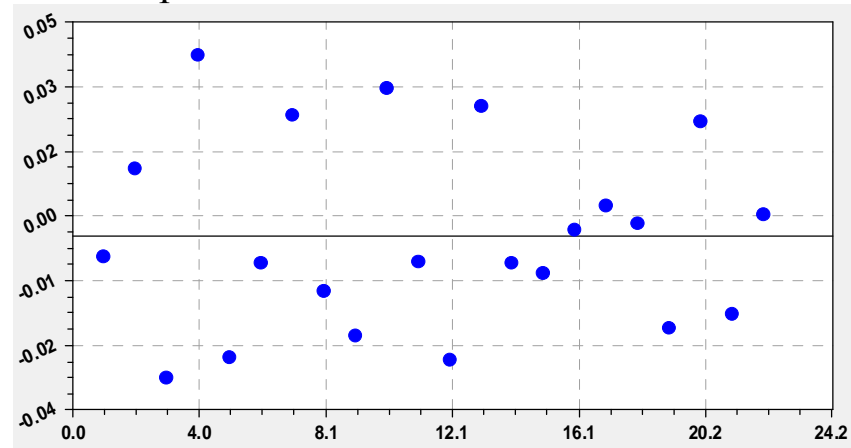

Остатки после модели (7)

Рисунок 7. Графики динамики доли залежси в СХУ Российской Федерации

Залежи нарастают по экспоненциальному закону, при этом стрессовое возбуждение постепенно убывает и со временем будет только медленный рост площади залежи по тренду. Таким образом, все семь показателей показывают, что на прогнозы колебания значений параметров СХУ почти не влияют. 
Заключение. Статистическое моделирование позволяет выявить высокоадекватные тренды и волновые составляющие динамики площади сельскохозяйственных земель по общей формуле (1). Удивительно, но волновые колебательные возмущения по всем семи показателям из данных таблицы 1 почти не влияют на прогноз [8]. Этот факт указывает, что российская земля является надежным источником существования российского населения.

Идентификация общей модели (1) может быть выполнена по динамике и других категорий земельного кадастра не только России, но и субъектов федерации. При этом статистическое моделирование нужно проводить ежегодно, дополняя таблицу 1 новыми данными за последующие годы. Результаты моделирования позволяют надеяться, что, наконец-то, будут приниматься осознанные повороты в земельной политике и в технологии землепользования, причем как по категориям земельного кадастра, так и по субъектам федерации.

Во всех моделях тренд получился с тремя и четырьмя членами. При этом конструкция у всех показателей одинаковая по общей модели (1): первый член является законом экспоненциальной гибели (отрицательный знак) или роста (положительный знак), а второй - биотехническим законом. При этом второй член вычитается (показывает кризис) или прибавляется. Таким образом, формулы динамики показывают высокую изменчивость параметров земельных ресурсов. Даже изменение на один год влияет на изменение параметров модели.

Несколько колебаний остались в прошлом и они, к радости, не влияют на прогноз [8]. Однако их изучение полезно с историографической [4] точки зрения, чтобы не повторять стихийные импульсные колебания, причем как в землепользовании, так и во всем национальном хозяйстве Российской федерации.

\section{Список литературы:}

1. Арзамасцев А.Д., Мазуркин П.М., Максимец Н.В. Факторный анализ сельскохозяйственного производства. Йошкар-Ола: МарГТУ, 2009. 388 с.

2. Государственный (национальный) доклад о состоянии и использовании земель в Российской Федерации в 2012 году. М.: Федеральная служба государственной регистрации, кадастра и картографии, 2013. 253 с.

3. Мазуркин П.М. Геоэкология: Закономерности современного естествознания. Йошкар-Ола: МарГТУ, 2006. 336 с. 
4. Мазуркин П.М. Историографический анализ динамики населения России // Международный журнал прикладных и фундаментальных исследований. 2009. № 5. C.56-69.

5. Мазуркин П.М. Динамика землепользования субъекта федерации // Землеустройство и кадастры: проблемы и пути их решения. Матер. Междунар. науно-практ. конф. в рамках пленарного засед. Совета УМО вузов по образ. в области землеустройства иикадастров / Под общ. ред. В.В. Вершинина. М.: ГУЗ, 2013. С. 94-99.

6. Мазуркин П.М. Идентификация статистических устойчивых закономерностей // Наука и мир: международ. научный журнал. 2013. № 3(3). С.28-33.

7. Мазуркин П.М. Коррелятивная вариация: учеб. пос. с грифомУМО РАЕ. Йошкар-Ола: Поволжский ГТУ, 2013. 120 с.

8. Мазуркин П.М. Прогноз землепользования в России // Землеустройство и кадастр недвижимости: проблем и пути их решения. Матер. научно-практ форума, посв. 235-летию со дня основания Госуд. ун-та по землеустройству / Под общ. ред. С.Н. Волкова, В.В. Вершинина. М.: ГУЗ, 2014. С. 61-67.

9. Мазуркин П.М. Решение 23-ой проблемы Гильберта Междисциплинарные исследования в области математического моделирования и информатики. Матер. 3-й научно-прак. internet-конф. Ульяновск: SIMJET, 2014. C 269-277.

10. Мазуркин П.М., Ильменев Г.Н., Салахутдинов Ф.Н. Закономерности кадастровой оценки сельскохозяйственных угодий (на примере Республики Марий Эл). Йошкар-Ола: МарГТУ-ФГУП МарГипрозем, 2002. 66 с.

11. Мазуркин П.М., Касьянов Ю.В. Динамика управления земельным фондом субъекта федерации // Регистрация - кадастр. 2012. № 2. С.16-22.

12. Мазуркин П.М., Михайлова С.И. Биотехническая оценка пойменного луга. М.: Изд-во «Академия естествознания», 2009. 279 с.

13. Мазуркин П.М., Михайлова С.И. Модели кадастровой оценки сельхозугодий // АПК: Экономика и управление. 2009. № 8. С.76-82.

14. Мазуркин П. М., Михайлова С.И. Территориальное экологическое равновесие $=$ Territprial ecological balance: аналит. обзор; Учреждение Рос. акад. наук Гос. публич. науч.-техн. б-ка Сиб. отд-ния РАН. Новосибирск: ГПНТБ СО РАН, 2010. 430 с. (Сер. Экология. Вып. 94).

15. Мазуркин П.М., Фадеев А.Н. Закономерности распределения земельного фонда (на примере РМЭ). Йошкар-Ола: МарГТУ, 2006. 127 с.

16. Михайлова С.И., Мазуркин П.М. Ландшафтно-экологическая роль пойменного луга малых рек. Йошкар-Ола: МарГТУ, 2011. 154 с.

17. Mazurkin P.M. Statistical modeling of entire prime numbers / International Journal of Engineering and Technical Research (IJETR) ISSN: 2321-0869, Volume2, Issue-8, August 2014. P.148-158.

18. Mazurkin P.M. Method of identification $/ / 14^{\text {th }}$ International multidisciplinary scientific geoconferenct \& SGEM2014. GeoConference jn NANO, BIO AND GREEN - TECHNOLOGIES FOR A SUSTAINABLE FUTURE. Conference proceedincs. Volume 1. Section Advances in Biotechnology. 17-26 June 2014. Albena, Bulgaria. P. 427-434. 